\title{
Spine stereotactic radiosurgery for metastatic thyroid cancer: a single-institution experience
}

\author{
David Boyce-Fappiano, MD, ${ }^{1}$ Olsi Gjyshi, MD, PhD, ${ }^{1}$ Todd A. Pezzi, MD, MBA, ${ }^{1}$ \\ Pamela K. Allen, PhD, ${ }^{1}$ Moaaz Solimman, MD, ${ }^{1}$ Nicolette Taku, MD, MPhil, MPH, ${ }^{1}$ \\ Michael B. Bernstein, MD, ${ }^{2}$ Maria E. Cabanillas, MD, ${ }^{3}$ Behrang Amini, MD, PhD, ${ }^{4}$ \\ Claudio E. Tatsui, MD, ${ }^{5}$ Laurence D. Rhines, MD, ${ }^{5}$ Xin A. Wang, PhD, ${ }^{6}$ Tina M. Briere, $\mathrm{PhD},{ }^{6}$ \\ Debra Nana Yeboa, MD, ${ }^{1}$ Andrew J. Bishop, MD, ${ }^{1}$ Jing Li, MD, PhD, ${ }^{1}$ and Amol J. Ghia, MD ${ }^{1}$
}

1Department of Radiation Oncology, The University of Texas MD Anderson Cancer Center, Houston, Texas; ${ }^{2}$ Department of Radiation Oncology, Memorial Sloan Kettering Cancer Center, New York, New York; and Departments of ${ }^{3}$ Endocrine Neoplasia and Hormonal Disorders, ${ }^{4}$ Radiology, ${ }^{5}$ Neurosurgery, and ${ }^{6}$ Radiation Physics, The University of Texas MD Anderson Cancer Center, Houston, Texas

\begin{abstract}
OBJECTIVE Patients with metastatic thyroid cancer have prolonged survival compared to those with other primary tumors. The spine is the most common site of osseous involvement in cases of metastatic thyroid cancer. As a result, obtaining durable local control (LC) in the spine is crucial. This study aimed to evaluate the efficacy of spine stereotactic radiosurgery (SSRS) in patients with metastatic thyroid cancer.

METHODS Information on patients with metastatic thyroid cancer treated with SSRS for spinal metastases was retrospectively evaluated. SSRS was delivered with a simultaneous integrated boost technique using single- or multiplefraction treatments. LC, defined as stable or reduced disease volume, was evaluated by examining posttreatment MRI, $\mathrm{CT}$, and PET studies.
\end{abstract}

RESULTS A total of 133 lesions were treated in 67 patients. The median follow-up duration was 31 months. Dose regimens for SSRS included $18 \mathrm{~Gy}$ in 1 fraction, $27 \mathrm{~Gy}$ in 3 fractions, and $30 \mathrm{~Gy}$ in 5 fractions. The histology distribution was $36 \%$ follicular, 33\% papillary, 15\% medullary, $13 \%$ Hurthle cell, and 3\% anaplastic. The 1-, 2-, and 5-year LC rates were $96 \%, 89 \%$, and $82 \%$, respectively. The median overall survival (OS) was 43 months, with 1 -, 2-, and 5 -year survival rates of $86 \%, 74 \%$, and $44 \%$, respectively. There was no correlation between the absolute biological equivalent dose (BED) and OS or LC. Patients with effective LC had a trend toward improved OS when compared to patients who had local failure: 68 versus 28 months ( $p=0.07)$. In terms of toxicity, 5 vertebral compression fractures $(2.8 \%)$ occurred, and only 1 case $(0.6 \%)$ of greater than or equal to grade 3 toxicity (esophageal stenosis) was reported.

CONCLUSIONS SSRS is a safe and effective treatment option with excellent LC and minimal toxicity for patients with metastatic thyroid cancer. No association with increased radiation dose or BED was found, suggesting that such patients can be effectively treated with reduced dose regimens.

https://thejns.org/doi/abs/10.3171/2019.12.SPINE191269

KEYWORDS SSRS; spine stereotactic radiosurgery; thyroid cancer; metastatic; radiation; oncology

$\mathrm{T}$ HYROID cancer is the most rapidly rising malignancy in the United States with an estimated 52,070 new cases in $2019 .{ }^{2}$ Fortunately, the 5 -year survival rates for thyroid cancer are among the highest of any disease site, approaching $98 \% .^{40}$ Despite excellent survival rates, approximately $4 \%$ of patients with thyroid cancer develop bone metastases that can significantly affect overall survival (OS) rates, long-term morbidity, and quality of life. ${ }^{12,31}$ Patients with osseous metastases have been shown to carry worse OS when compared to patients with metastatic disease not involving the bone-likely due to the high rate of symptomatic skeletal events, such as spinal cord compression and fractures. ${ }^{12}$ The spine is the most common site of osseous metastatic disease in thyroid can-

ABBREVIATIONS BED = biological equivalent dose; $\mathrm{CTCAE}=$ Common Terminology Criteria for Adverse Events; $\mathrm{CTV}=$ clinical target volume; GTV = gross tumor volume; $\mathrm{LC}=$ local control; OS = overall survival; RT = radiation therapy; SSRS = spine stereotactic radiosurgery; TKI = tyrosine kinase inhibitor.

SUBMITTED October 24, 2019. ACCEPTED December 3, 2019.

INCLUDE WHEN CITING Published online February 14, 2020; DOI: 10.3171/2019.12.SPINE191269. 
cer patients, with involvement often causing significant pain and neurological compromise ${ }^{27}$ Due to the increased survival rates compared to other malignancies, optimal local control (LC) in the spine is paramount to avoid longterm morbidity and neurological sequelae. Furthermore, with bone metastases yielding worse OS paired with the recent advancements in therapy, including targeted therapy, immunotherapy, and the oligometastatic paradigm, improved LC may result in improved survival rates. This has been demonstrated recently in the oligometastatic setting using both surgery and stereotactic body radiation therapy (RT) ${ }^{23,34}$ In addition, previous data have also shown excellent survival rates in patients with isolated spine disease treated with spine stereotactic radiosurgery (SSRS). ${ }^{25}$

Treatment options for spinal metastases include steroids, conventional RT, SSRS, surgery, or any combination of these modalities. Decisions regarding treatment are made using a combination of factors that have been described in the NOMS (neurologic, oncologic, mechanical, and systemic) framework. ${ }^{28}$ This incudes neurological factors such as the presence of acute deficits, oncological factors such as tumor histology, radiosensitivity, metastatic burden, the mechanical stability of the spine, and surgical candidacy. ${ }^{28}$ Patients with acute neurological compromise or mechanical instability of the spine should receive surgery if deemed to be appropriate candidates. For patients not requiring operative management, RT using a conventional or stereotactic approach can be performed. Conventional RT is often utilized in patients with significant cord compression or acute neurological deficits (in patients who are nonoperative candidates) and in patients with poor performance status or with high metastatic burden-owing to the fact RT can be performed as an urgent same-day treatment due to the simplicity of treatment planning with conventional approaches. SSRS has the advantage of delivering ablative doses of radiation with submillimeter precision, thus providing the opportunity for improved LC while reducing normal tissue toxicity. LC rates for SSRS have been shown to be approximately $90 \%$ and $80 \%$ at 1 and 2 years, respectively. ${ }^{1,5,10 \text {, }}$ 17,21,43 Beyond effective LC rates, SSRS is well tolerated and toxicity rates are low.,38 We previously reported our early experience in treating patients with metastatic thyroid cancer using SSRS and demonstrated effective LC. ${ }^{4}$ Since that study, we have experienced increased volume and therefore aim to expand upon our previous results to report outcomes of SSRS in a larger cohort of patients with metastatic thyroid cancer and to evaluate factors associated with LC.

\section{Methods \\ Patients}

The records of patients with metastatic thyroid cancer in whom spinal involvement was treated with SSRS from January 2004 to December 2018 were retrospectively evaluated after we obtained institutional review board approval. The study population included two cohorts of patients previously enrolled in a combined phase I/II singleinstitution study, in addition to patients who were treated off protocol. A total of 67 patients' medical records were reviewed, and patient, tumor, and treatment data were extracted for analysis.

\section{Treatment}

Patients in this study were treated with image-guided intensity-modulated SSRS; the CT guidance system was the EXaCT Targeting System CT-on-rails or the Trilogy system with onboard cone-beam CT (Varian Medical Systems), as previously described.9.,39 Since 2014, patients were treated with TrueBeam with onboard cone-beam CT and ExacTrac Dynamic (Brainlab) guidance. Patient immobilization was completed using a BodyFix stereotactic body frame system (Elekta) and aligned with a stereotactic localizer and target-positioning frame (Integra-Radionics). Treatment planning was completed using intensitymodulated RT inverse-treatment software (Pinnacle, Philips Medical Systems). CT myelography with intrathecal injection of contrast medium (Omnipaque, Amersham Health) was performed when MRI alone was insufficient to clearly delineate the spinal cord. Thorough quality-assurance procedures were completed by a dedicated radiation physicist, and all target positions were verified by the treating radiation oncologist.

Delineation of the gross tumor volume (GTV) and clinical target volume (CTV) for primary cases was based on consensus guidelines for SSRS contouring. ${ }^{15}$ The GTV was defined as visible tumor on an MR image fused with the planning CT scan, and the CTV was defined as at-risk contiguous bone marrow or soft tissue in cases with paraspinal disease. No additional margin or planning treatment volume was utilized. In the postoperative setting, target volumes were constructed similarly to the recently published consensus postoperative SSRS guidelines. ${ }^{36}$ The GTV was defined as any gross residual disease and/ or the postoperative bed, with the CTV representing the contiguous bone marrow space and any additional postoperative bed at risk for microscopic disease. SSRS was delivered using a simultaneous integrated boost technique in a single-fraction regimen (18-24 Gy) or in multifraction regimens (25-30 Gy in 3-5 fractions); the multifraction treatments were delivered on alternating days. Our current practice is to utilize single-fraction treatments for cases involving radiation-naïve sites and multifraction regimens for cases involving reirradiation. Multifraction regimens in this study were performed in either patients undergoing reirradiation or patients enrolled in institutional phase I and II studies requiring alternative dose regimens. To account for and appropriately compare the various fractionation schemes, a biological equivalent dose (BED) was calculated for the prescription based on the $\alpha / \beta$ value of $10 \mathrm{~Gy}$ for tumor effect. A spinal cord constraint of 0.01 $\mathrm{cm}^{3}<10-12$ Gy was commonly utilized. An example of a treatment plan can be visualized in Fig. 1 .

\section{Follow-Up and Endpoints}

Patients were followed until the last known follow-up date or the date of death. LC, defined as stable or reduced disease volume, was evaluated by posttreatment MRI, CT, and PET.

The median follow-up duration for the entire cohort 

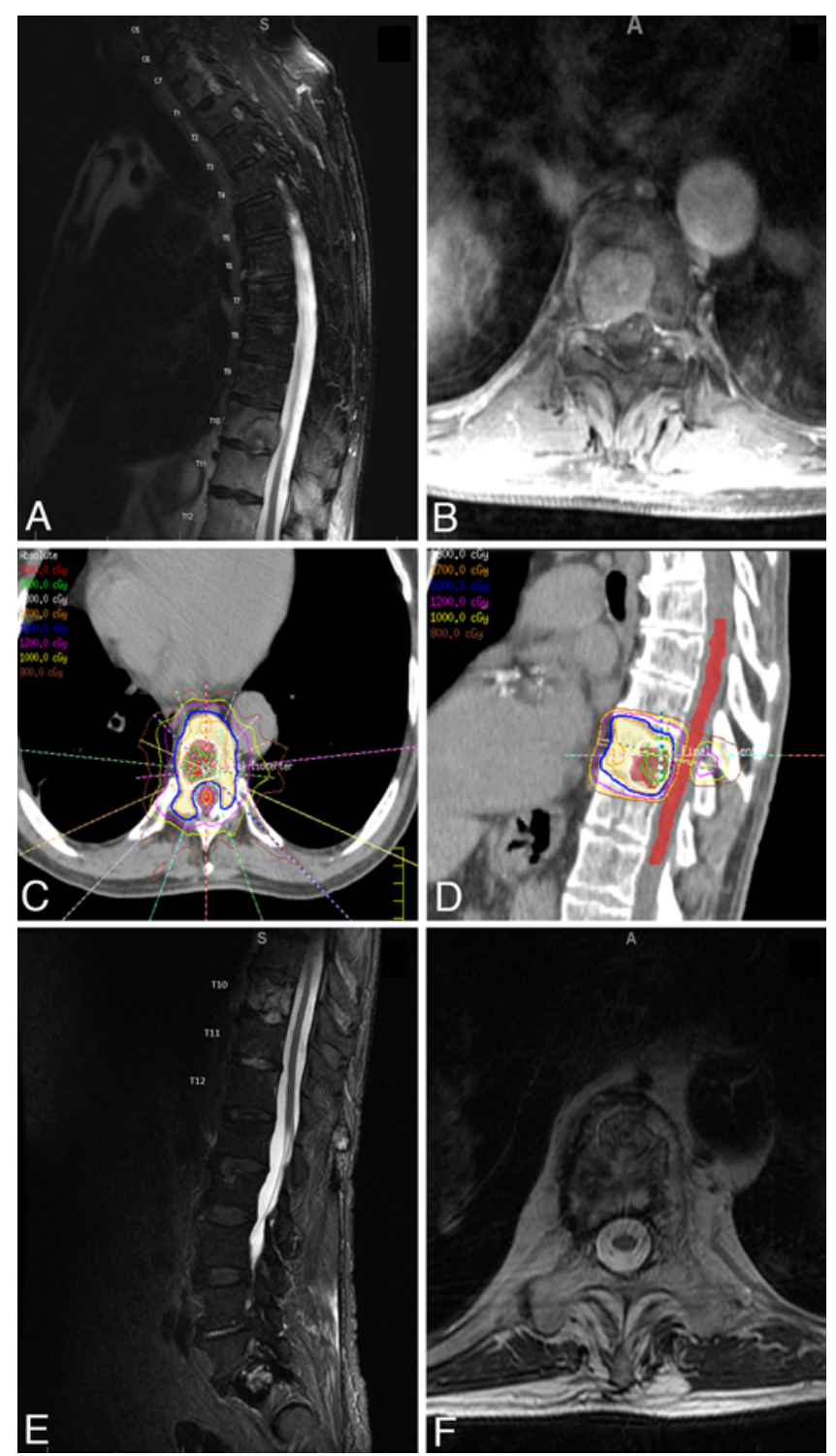

FIG. 1. A male patient with oligometastatic papillary cancer with Bilsky $1 \mathrm{~b}$ compression at T10. Pretreatment T2-weighted sagittal (A) and axial (B) MR images displaying Bilsky $1 \mathrm{~b}$ compression at T10. Axial (C) and sagittal (D) CT simulation slices displaying the SSRS treatment plan using a simultaneous integrated boost to $24 \mathrm{~Gy}$ in 1 fraction to the GTV (red target, white isodose) and 18 Gy to the CTV, including the vertebral body and pedicles (yellow target, blue isodose). Long-term follow-up posttreatment T2-weighted sagittal $(E)$ and axial $(F)$ MR images at 72 months post-SSRS displaying complete response, demonstrating the effectiveness and durability of SSRS for thyroid cancer. Figure is available in color online only.

was 19 months (range 1-121 months), and for all living patients it was 31 months (range 10-121 months). Acute (defined as less than 3 months) and long-term toxicities were prospectively recorded for patients treated on protocol (53\%); otherwise, toxicities were retrospectively graded using the Common Terminology Criteria for Adverse Events (CTCAE) version 4.03. Patients were seen every 3 months for physical examination and MRI of the spine to assess for radiological tumor recurrence. Local recurrenc- es were defined as radiological evidence of progression, as identified by the reading radiologist.

\section{Statistical Analysis}

Data analysis was performed using Stata/MP 15.0 statistical software. The survival function was carried out using Kaplan-Meier estimates. The log-rank test was used to assess the equality of the survivor function across groups. The Cox proportional hazards model was used for multivariate analysis to assess the effect of patient, tumor, and other predictor factors of significance on OS and local tumor control. The estimated hazard is reported. The Wald test was used to assess the role of covariates in the model. All factors found to have a $p$ value of 0.25 or less on univariate analysis were included in the multivariable analysis, with each factor eliminated in a stepwise manner until the most significant variables were identified. The Wald test was used to assess the role of covariates in the model. Competing risk regression analysis was done according to the method of Fine and Gray with a similar selection of predictive factors for multivariable analysis. ${ }^{18}$ Subhazard ratios are reported for the failure event of primary interest (local tumor control), with death without local failure as the competing event reported.

\section{Results}

\section{Patient and Treatment Characteristics}

The patient characteristics are provided in Table 1 and the treatment characteristics are included in Table 2. A total of 133 lesions were treated in 67 patients. The median follow-up was 31 months for living patients. There was nearly an equal proportion of men and women at $51 \%$ and $49 \%$, respectively. The median age of patients was 60 years. Follicular was the most common thyroid histology at $36 \%$, followed by papillary $33 \%$, medullary $15 \%$, Hurthle cell $13 \%$, and anaplastic $3 \%$. In terms of malignant spinal cord compression grading, the following was noted: grade 0 in $55 \%$, 1a in $11 \%, 1 \mathrm{~b}$ in $20 \%$, and 2 in $8 \%$ of patients. SSRS treatment was the primary modality of care in $62 \%$ of cases, while $38 \%$ received SSRS in the adjunctive or salvage setting. With regard to other treatment pathways, $19 \%$ of cases underwent surgery prior to SSRS, $29 \%$ had prior external-beam RT, and $89 \%$ of patients had received iodine-131 treatment. In addition, $66 \%$ of patients were on tyrosine kinase inhibitor (TKI) therapy throughout their course of treatment. A majority of cases (76\%) involved the treatment of a single vertebral body. For single-fraction treatments, a dose-fractionation scheme of $18 \mathrm{~Gy}$ in 1 (44\%) or $24 \mathrm{~Gy}$ in 1 (10\%) fraction was utilized. For multifraction treatments, a scheme of 27 Gy in $3(41.4 \%)$ or 30 Gy in $5(3.8 \%)$ fractions was utilized, with the exception of 1 patient who was treated with 25 Gy in 5 (1.5\%) fractions.

\section{Local Control}

The 1-, 2-, and 5-year LC rates were 96\%, 89\%, and $82 \%$, respectively (Fig. 2). Median LC was not reached. A total of 12 failures were found in this cohort. Review of the pattern of failures revealed $58 \%$ in field, $25 \%$ marginal epidural, $17 \%$ out of field, and $18 \%$ marginal paraspinal. Univariate analysis detailing factors predicting LC 
TABLE 1. Patient characteristics

\begin{tabular}{|c|c|c|}
\hline Characteristic & No. & $\%$ \\
\hline Patients & 67 & \\
\hline Lesions & 133 & \\
\hline Vertebral bodies treated & 179 & \\
\hline Median age (range) & $60(28-80)$ & \\
\hline \multicolumn{3}{|l|}{ Sex* } \\
\hline Male & 34 & $51 \%$ \\
\hline Female & 33 & $49 \%$ \\
\hline \multicolumn{3}{|l|}{ Histology* } \\
\hline Follicular & 24 & $35.8 \%$ \\
\hline Papillary & 22 & $32.8 \%$ \\
\hline Medullary & 10 & $14.9 \%$ \\
\hline Hurthle cell & 9 & $13.4 \%$ \\
\hline Anaplastic & 2 & $3.0 \%$ \\
\hline \multicolumn{3}{|l|}{ Bilsky MSCC grade† } \\
\hline 0 & 73 & $55 \%$ \\
\hline $1 \mathrm{a}$ & 15 & $11 \%$ \\
\hline $1 b$ & 26 & $20 \%$ \\
\hline $1 c$ & 0 & 0 \\
\hline 2 & 10 & $8 \%$ \\
\hline 3 & 0 & 0 \\
\hline \multicolumn{3}{|l|}{ Prior treatment† } \\
\hline 131 & 118 & $88.72 \%$ \\
\hline Radiation treatment & 38 & $28.57 \%$ \\
\hline Surgery & 25 & $18.80 \%$ \\
\hline
\end{tabular}

${ }^{131} \mid=$ iodine-131; MSCC = malignant spinal cord compression.

* Percentages are based on the number of patients.

$\dagger$ Percentages are based on the number of lesions.

are shown in Table 3. On multivariate analysis when accounting for sex, treatment type, and progression at distant sites, progression at distant sites was the only factor that emerged as significantly associated with local failure (HR $5.0,95 \%$ CI $1.07-23.39 ; p=0.04)$. In a separate competing risk analysis that was performed to account for risk of death, the only factor that was significantly associated with LC was female sex (HR 0.18, 95\% CI 0.04-0.79; $\mathrm{p}=0.04$ ).

\section{Overall Survival}

The median OS was 43 months, with 1-, 2-, and 5-year survival rates of $86 \%, 74 \%$, and $44 \%$, respectively (Fig. 3). A total of 13 patients in this analysis were deceased; all cases were attributed to progression of systemic disease. There was a trend toward worse OS in patients who experienced local failure (28 months vs 68 months), reaching near-significant significance $(\mathrm{p}=0.07)$ (Fig. 4). The univariate analysis for factors predicting OS is displayed in Table 4. On multivariate analysis, being treated with more than 1 fraction was associated with improved OS (HR 2.28, 95\% CI 1.16-4.46; $\mathrm{p}=0.016$ ).

\section{Toxicity}

Based on the CTCAE version 4.3, there were 28 treat-
TABLE 2. Summary of radiation-related characteristics

\begin{tabular}{lrr}
\hline \multicolumn{1}{c}{ Characteristic } & No. & $\%$ \\
\hline Treatment intent & & \\
\hline Primary & 70 & $52.6 \%$ \\
\hline Adjuvant/salvage & 63 & $47.4 \%$ \\
\hline No. of vertebral bodies treated & \\
\hline 1 & 101 & $75.9 \%$ \\
\hline 2 & 18 & $13.5 \%$ \\
\hline 3 & 14 & $10.5 \%$ \\
\hline Region of spine treated & & \\
\hline Cervical & 20 & $15.0 \%$ \\
\hline Thoracic & 68 & $51.1 \%$ \\
\hline Lumbar & 36 & $27.1 \%$ \\
\hline Sacral & 9 & $6.8 \%$ \\
\hline Dose-fractionation schedule (Gy/no. of fractions) & & \\
\hline Single fraction & 71 & $53.4 \%$ \\
\hline $18 / 1$ & 58 & $43.6 \%$ \\
\hline $24 / 1$ & 13 & $9.8 \%$ \\
\hline Multifraction & 62 & $46.6 \%$ \\
\hline $25 / 5$ & 2 & $1.5 \%$ \\
\hline $27 / 3$ & 55 & $41.4 \%$ \\
\hline
\end{tabular}

ment-related acute toxicities (21\%) of the 133 lesions, of which all but 1 (96.4\%) were grade 1 and 2 toxicities. Fatigue was the most common among the acute toxicity cases, representing $29 \%$ of adverse events, followed by acute nausea at $21 \%$. Two cases of grade 2 esophagitis were noted. The single case of greater than or equal to grade 3 toxicity was esophageal stenosis in a patient who received $18 \mathrm{~Gy}$ in 1 fraction. Pain flare was uncommon but occurred in 8 cases $(6 \%)$ of the 133 lesions. With $66 \%$ of patients being on TKIs, the incidence of radiation recall was also investigated and found to occur in only $2 \%$ of patients on TKI therapy. Both cases of radiation recall were of minimal severity. In terms of late toxicity, 5 vertebral compression fractures (3\%) occurred (a total of 179 vertebral bodies were treated). Two cases of mild sensory radiculopathy were noted; otherwise, no significant neurological toxicities including radiation myelopathy were observed.

\section{Discussion}

This report represents the largest study exploring the benefits of SSRS for patients with thyroid cancer. Our previous report included a total of 23 patients with 27 treated lesions, with 2- and 3-year LC rates of $88 \%$ and $79 \%$, respectively. ${ }^{4}$ Our current study includes 67 patients with 133 treated lesions with similar LC rates of $96 \%, 89 \%$, and $82 \%$ at 1-, 2-, and 5-year follow-up examinations, respectively. Previous data regarding the effectiveness of SSRS for spinal metastasis have shown LC rates on the order of approximately $90 \%$ at 1 year and $80 \%$ at 2 years. The improved LC rates in this cohort likely speak to the relative radiosensitivity of thyroid cancer. This holds true within our analysis as there was no benefit with increasing 


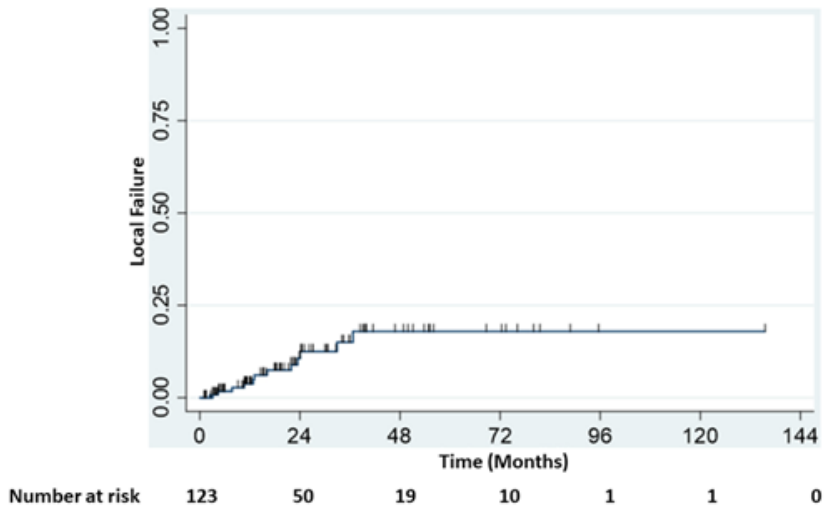

FIG. 2. Local failure analysis for patients with metastatic thyroid cancer treated with SSRS. Figure is available in color online only.

radiation dose, increasing fractionation, or BED in terms of LC or OS. An example can be seen in Fig. 1, where a patient with oligometastatic papillary cancer with a grade $1 \mathrm{~b}$ compression at T10 was effectively treated with SSRS delivering $18 \mathrm{~Gy}$ in a single fraction. His follow-up scans, noted in Fig. 1, showed complete resolution of epidural disease, with 72-month posttreatment imaging reflecting the effectiveness and durability of SSRS for thyroid cancer. While no data are available specifically evaluating the efficacy of conventional RT for thyroid cancer spinal metastases, the overall radiographic control rate for all histologies is quite poor, on the order of $20 \%$ at 2 years. ${ }^{26}$ This is drastically lower than the LC rates achieved with SSRS and a fundamental reason why SSRS is the preferred radiation approach for appropriately selected patients. On the other hand, data regarding resection for thyroid cancer spinal metastases show excellent 5-year LC rates of $90 \%$ with total en bloc spondylectomy. ${ }^{16}$ However this drops substantially, reaching $57 \%$ when only subtotal resections are performed.$^{16}$ This highlights the importance of patient selection for treatment; in cases where total en bloc spondylectomy is achievable, this would be the ideal treatment approach given the superior LC. With that being said, in cases where total en bloc spondylectomy is not achievable, such as in those with significant paraspinal disease or multilevel vertebral body involvement, SSRS would be preferred due to improved LC rates when compared to subtotal resection.

Due to the excellent LC rates seen in this study, there seems to be a limited role for biological dose escalation (e.g., $24 \mathrm{~Gy} / 1$ fraction) for this cohort of patients. In contrast, data regarding LC in more radioresistant histological types such as sarcomas display a strong correlation between SSRS dose and LC rates. ${ }^{6,22,29,44}$ In particular, renal cell carcinoma is a radioresistant histology that has been shown to have suboptimal rates of LC with conventional SSRS doses. A study comparing dose regimens for renal cell carcinoma found a statistically significant improved rate of LC with the use of single-fraction treatments of $\geq 24$ Gy vs $<24$ Gy with a 3-year LC rate of $88 \%$ and $21 \%$, respectively $(\mathrm{p}=0.001) .{ }^{4}$ Our own experience as a combined phase I/II trial has been published comparing 24 Gy in 1 fraction vs 27 Gy in 3 fractions for renal cell
TABLE 3. Analysis for LC

\begin{tabular}{|c|c|c|c|}
\hline Variable & Comparison & $\mathrm{HR}(95 \% \mathrm{Cl})$ & $\begin{array}{c}p \\
\text { Value }\end{array}$ \\
\hline \multicolumn{4}{|l|}{ Univariate analysis } \\
\hline \multicolumn{4}{|l|}{ Sex } \\
\hline Female & Male & $4.12(0.90-18.85)$ & 0.07 \\
\hline \multicolumn{4}{|l|}{ Age } \\
\hline Continuous & Continuous & $1.00(0.95-1.05)$ & 0.89 \\
\hline $50-69$ yrs & $50-69$ yrs & $1.27(0.27-5.90)$ & 0.76 \\
\hline 70 yrs & $\geq 70$ yrs & $0.74(0.07-8.18)$ & 0.81 \\
\hline \multicolumn{4}{|l|}{ Histology } \\
\hline Papillary & Follicular & $2.10(0.59-7.48)$ & 0.25 \\
\hline Other & Follicular & $0.61(0.11-3.33)$ & 0.57 \\
\hline \multicolumn{4}{|l|}{ Prior RT } \\
\hline Yes & No & $0.68(0.15-3.09)$ & 0.61 \\
\hline \multicolumn{4}{|l|}{ Prior surgery } \\
\hline Yes & No & $0.40(0.05-3.07)$ & 0.38 \\
\hline \multicolumn{4}{|l|}{ Prior ${ }^{131}$} \\
\hline Yes & No & $2.11(0.27-16.33)$ & 0.61 \\
\hline \multicolumn{4}{|l|}{ Primary treatment } \\
\hline No & Yes & $0.40(0.09-1.83)$ & 0.24 \\
\hline \multicolumn{4}{|c|}{$\begin{array}{l}\text { No. of vertebral bodies } \\
\text { treated }\end{array}$} \\
\hline 2 & 1 & $0.58(0.07-4.58)$ & 0.61 \\
\hline 3 & 1 & $0.92(0.12-7.26)$ & 0.941 \\
\hline \multicolumn{4}{|l|}{ No. of fractions } \\
\hline 3 & 1 & $0.52(0.14-1.91)$ & 0.32 \\
\hline 5 & 1 & $0.52(0.14-1.91)$ & 0.32 \\
\hline$>1$ & 1 & $0.48(0.13-1.78)$ & 0.271 \\
\hline \multicolumn{4}{|l|}{ BED } \\
\hline Continuous & Continuous & $1.00(0.9-1.07)$ & 0.99 \\
\hline$>80$ & $<80$ & $0.96(0.12-7.44)$ & 1.0 \\
\hline \multicolumn{4}{|c|}{ Progression at other sites } \\
\hline Yes & No & $3.99(0.87-18.32)$ & 0.075 \\
\hline \multicolumn{4}{|l|}{ Multivariate analysis } \\
\hline \multicolumn{4}{|c|}{ Progression at other sites } \\
\hline Yes & No & $5.00(1.07-23.39)$ & 0.041 \\
\hline \multicolumn{4}{|l|}{ Sex } \\
\hline Female & Male & $4.94(1.07-22.82)$ & 0.041 \\
\hline \multicolumn{4}{|c|}{ Primary treatment } \\
\hline No & Yes & $0.24(0.05-1.13)$ & 0.071 \\
\hline
\end{tabular}

carcinoma and displayed statistically significant improved $\mathrm{LC}$ at 1 year (95\% vs 71\%) and 2 years (86\% vs 55\%) favoring single-fraction treatment. ${ }^{22}$ Comparing these rates to the current study where more than $85 \%$ of patients were treated with standard dose regimens (18/1 or 27/3), one can conclude that due to the intrinsic radiosensitivity of thyroid cancer, there is no need to utilize dose-escalated regimens, thus minimizing any long-term toxicities that these patients may develop.

In terms of factors predicting LC rates, female sex was 


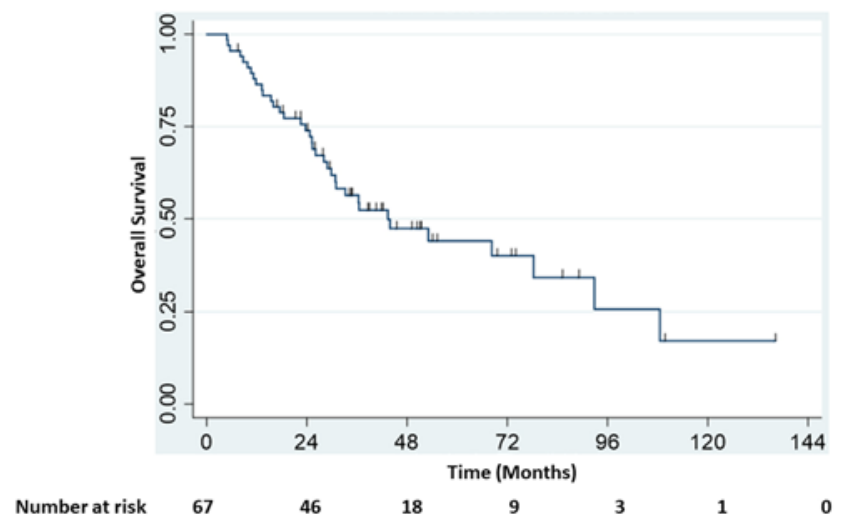

FIG. 3. Kaplan-Meier survival analysis for patients with metastatic thyroid cancer treated with SSRS. Figure is available in color online only.

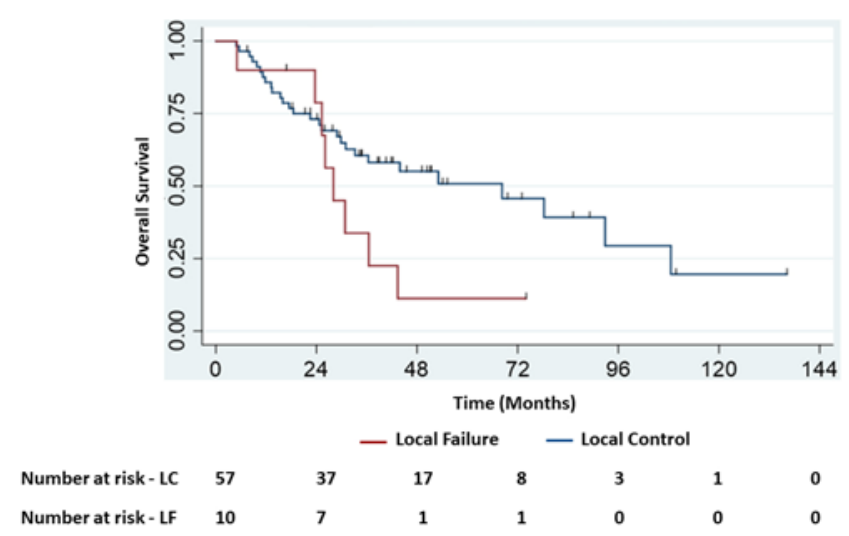

FIG. 4. Kaplan-Meier survival analysis for patients with metastatic thyroid cancer treated with SSRS, stratified by local failure (LF; red) versus LC (blue). Figure is available in color online only.

associated with improved LC, while progression at other distant sites was associated with worse LC in the spine. Females are significantly more likely to develop thyroid cancer, and thus this finding could be reflective of the higher incidence of the disease within this population or perhaps due to underlying biology, such as hormonal differences. The association between local and distant failure in this cohort is likely reflective of more aggressive cancers with resistance to both systemic and local treatment.

Beyond being effective as a primary modality, SSRS also offers the advantage of being an effective salvage therapy in the case of failed conventional RT or surgery. Forty-seven percent of patients in this study were treated with SSRS as a second-line local therapy; despite this approach, LC remained exceedingly high. These data confirm that SSRS is an effective primary and adjuvant/salvage treatment option for patients with metastatic thyroid cancer.

The median OS for this study was 43 months, with 1-, $2-$, and 5-year survival rates of $86 \%, 74 \%$, and $44 \%$, respectively. Prior studies have shown median OS rates ranging from approximately 7 to 30 months for the patients with
TABLE 4. Analysis for OS

\begin{tabular}{|c|c|c|c|}
\hline Variable & Comparison & $\mathrm{HR}(95 \% \mathrm{Cl})$ & $\begin{array}{c}p \\
\text { Value }\end{array}$ \\
\hline \multicolumn{4}{|c|}{ Univariate analysis } \\
\hline \multicolumn{4}{|c|}{ Sex } \\
\hline Female & Male & $0.92(0.48-1.78)$ & 0.81 \\
\hline \multicolumn{4}{|l|}{ Age } \\
\hline Continuous & Continuous & $1.02(0.99-1.05)$ & 0.25 \\
\hline $50-69$ yrs & $<50$ yrs & $0.981(0.45-2.17)$ & 0.97 \\
\hline 70 yrs & $<50$ yrs & $1.38(0.48-3.96)$ & 0.55 \\
\hline \multicolumn{4}{|l|}{ Histology } \\
\hline Papillary & Follicular & $1.51(0.70-3.25)$ & 0.30 \\
\hline Other & Follicular & $0.59(0.25-1.36)$ & 0.22 \\
\hline \multicolumn{4}{|l|}{ Prior RT } \\
\hline Yes & No & $1.97(0.99-3.90)$ & 0.052 \\
\hline \multicolumn{4}{|l|}{ Prior surgery } \\
\hline Yes & No & $1.14(0.55-2.38)$ & 0.72 \\
\hline \multicolumn{4}{|l|}{ Prior ${ }^{131}$ I } \\
\hline Yes & No & $1.24(0.48-3.20)$ & 0.66 \\
\hline \multicolumn{4}{|c|}{ Primary treatment } \\
\hline No & Yes & $1.51(0.78-2.90)$ & 0.22 \\
\hline \multicolumn{4}{|c|}{$\begin{array}{l}\text { No. of vertebral } \\
\text { bodies treated }\end{array}$} \\
\hline 2 & 1 & $1.47(0.62-3.44)$ & 0.38 \\
\hline 3 & 1 & $3.15(1.26-7.89)$ & 0.0014 \\
\hline \multicolumn{4}{|l|}{ Spine location } \\
\hline Thoracic & Cervical & $0.83(0.33-2.11)$ & 0.70 \\
\hline Lumbar & Cervical & $1.14(0.39-3.31)$ & 0.81 \\
\hline Sacrum & Cervical & $1.38(0.35-5.56)$ & 0.65 \\
\hline \multicolumn{4}{|l|}{ No. of fractions } \\
\hline 3 & 1 & $2.30(1.15-4.59)$ & 0.018 \\
\hline 5 & 1 & $2.14(0.60-7.62)$ & 0.24 \\
\hline$>1$ & 1 & $2.28(1.16-4.46)$ & 0.016 \\
\hline \multicolumn{4}{|l|}{ BED } \\
\hline Continuous & Continuous & $0.99(0.95-1.03)$ & 0.65 \\
\hline$>80$ & $<80$ & $0.99(0.16-2.85)$ & 0.65 \\
\hline \multicolumn{4}{|c|}{$\begin{array}{l}\text { Progression at other } \\
\text { sites }\end{array}$} \\
\hline Yes & No & $1.57(0.79-3.13)$ & 0.20 \\
\hline \multicolumn{4}{|c|}{ Multivariate analysis } \\
\hline \multicolumn{4}{|c|}{ No. of fractions } \\
\hline$>1$ & 1 & $2.28(1.16-4.46)$ & 0.016 \\
\hline
\end{tabular}

spinal metastases undergoing SSRS. ${ }^{3,25,42}$ The improved OS in this cohort is likely due to the better prognosis of patients with thyroid cancer harboring spinal metastases compared to other primary histologies. However, compared to our previous study of patients with thyroid cancer, there is a 13 -month increase in median OS. ${ }^{4}$ This finding likely reflects the improvement in systemic therapy for patients with thyroid cancer, particularly the emergence of new targeted agents and immunotherapy. ${ }^{32}$ Improved OS 
was noted in patients treated with multifraction regimens compared to single-fraction treatment. Given that LC rates were not significantly different between single- and multiple-fraction approaches and that significance was lost on competing risk analysis, this difference is likely not clinically significant and may be an artifact of a higher proportion of multifraction patients being participants in clinical trials.

The incidence of thyroid cancer has been rising over the last decade. ${ }^{2,40}$ With excellent survival rates and the propensity for thyroid cancer to involve the spine, the importance of achieving durable LC is vital. In addition to the improvement in quality of life, recent evidence has shown overall and progression-free survival benefits from obtaining LC in the oligometastatic setting. ${ }^{23,25,34} \mathrm{~A}$ median OS of 76 months has also been reported in cases of solitary spinal metastasis treated with SSRS at our institution, and the presence of oligometastatic spinal disease has been incorporated into a validated prognostic scale for patients treated with SSRS. ${ }^{25,41}$ With a vast majority of patients in this study having fewer than 10 metastatic sites, the current data support this notion as patients with improved LC in the spine were found to have an improved OS of 68 months versus 28 months for patients with local failure, reaching near statistical significance $(\mathrm{p}=0.07)$.

In terms of toxicity, SSRS is well tolerated. Acute toxicity rates of fatigue, nausea, and esophagitis in this report were consistent with those of prior studies. ${ }^{19,24}$ A pain flare was only reported in $6 \%$ of cases, representing a significant decrease from prior published rates of $20 \%-70 \% .^{11,35}$ The latter report utilized single-fraction doses of 20-24 Gy, providing a rationale for the exceedingly elevated painflare rate of nearly $70 \% .{ }^{11}$ One late grade 3 event $(0.75 \%)$ occurred within this cohort, in which a case of esophageal stenosis was observed in a 35-year-old woman who initially received external-beam RT of $30 \mathrm{~Gy}$ in 10 fractions followed by salvage SSRS of $18 \mathrm{~Gy}$ in a single fraction to a T8 lesion. Rates of late grade 3 esophageal toxicity with SSRS have been reported to be $5 \%$ when treating lesions directly adjacent to the esophagus. ${ }^{14}$ This report utilized a median dose of $24 \mathrm{~Gy}$, explaining the increased rate of esophageal toxicity noted. ${ }^{14}$ In terms of other late-onset toxicities, a $2.8 \%$ incidence of vertebral compression fractures was noted, which is significantly lower than the $12 \%$ that has been previously reported. ${ }^{7}$ This is likely due to the reduced dose-fractionation scheme in the present study, as previous work suggests an increased incidence of vertebral compression fractures when single-fraction doses > 19 Gy are utilized. These findings highlight the importance of effectively adjusting the dose based on the intrinsic radiosensitivity of the tumor. As in the case of this analysis, the use of low-dose, single-fraction SSRS (18 Gy) not only was adequate to provide excellent LC but also correspondingly appears to be associated with lower rates of acute and chronic toxicity. Multiple prior case reports have displayed radiation recall dermatitis related to sorafenib and other TKIs. ${ }^{13,30,33}$ This adverse event can be quite severe, resulting in significant morbidity for patients, and thus is a feared complication of radiation treatment for thyroid cancer patients. ${ }^{13,30,33}$ Given the benefits of TKIs and their increasing use in patients with metastatic thyroid cancer, it is important to better determine the incidence and severity of this event. ${ }^{8}$ In the present study, the rate of radiation recall dermatitis for patients on TKIs was noted to be only $2 \%$, with both cases resulting in a mild reaction. This provides some reassurance of the use of RT for patients receiving TKI therapy.

This study is subject to the inherent limitations of any retrospective analysis. Overall, the sample size is small to moderate ( $\mathrm{n}=67$ patients with 133 lesions). However, when considering the available data on this subject, to the best of our knowledge, this is the largest analysis of SSRS for patients with metastatic thyroid cancer. Retrospective collections of data, particularly with regard to toxicity, are less than ideal. While a proportion of the data was retrospectively collected, more than half of the patients included in this analysis were enrolled in a combined phase I/II clinical trial at our institution, thus improving the robustness of this analysis.

\section{Conclusions}

SSRS is an extremely effective and safe treatment option for patients with spinal metastases in both the primary and adjuvant setting. The benefits of SSRS appeared to be enhanced in patients with thyroid cancer due a combination of factors, including possible intrinsic radiosensitive and improved long-term survival rates necessitating the need for effective LC. Excellent LC outcomes underscore the radiosensitive nature of thyroid cancer and suggest that escalated doses are not needed for tumor control. Due to the advancements in systemic therapy options and the corresponding improvements in OS, the demand for SSRS in patients with metastatic thyroid cancer will continue to increase.

\section{References}

1. Amdur RJ, Bennett J, Olivier K, Wallace A, Morris CG, Liu $\mathrm{C}$, et al: A prospective, phase II study demonstrating the potential value and limitation of radiosurgery for spine metastases. Am J Clin Oncol 32:515-520, 2009

2. American Cancer Society: Key statistics for thyroid cancer. Atlanta: ACS (https://www.cancer.org/cancer/thyroid-cancer/ about/key-statistics.html) [Accessed December 20, 2019]

3. Balagamwala EH, Miller JA, Reddy CA, Angelov L, Suh JH, Tariq MB, et al: Recursive partitioning analysis is predictive of overall survival for patients undergoing spine stereotactic radiosurgery. J Neurooncol 137:289-293, 2018

4. Bernstein MB, Chang EL, Amini B, Pan H, Cabanillas M, Wang XA, et al: Spine stereotactic radiosurgery for patients with metastatic thyroid cancer: secondary analysis of phase I/II trials. Thyroid 26:1269-1275, 2016

5. Bishop AJ, Tao R, Guadagnolo BA, Allen PK, Rebueno NC, Wang XA, et al: Spine stereotactic radiosurgery for metastatic sarcoma: patterns of failure and radiation treatment volume considerations. J Neurosurg Spine 27:303-311, 2017

6. Bishop AJ, Tao R, Rebueno NC, Christensen EN, Allen PK, Wang XA, et al: Outcomes for spine stereotactic body radiation therapy and an analysis of predictors of local recurrence. Int J Radiat Oncol Biol Phys 92:1016-1026, 2015

7. Boyce-Fappiano D, Elibe E, Schultz L, Ryu S, Siddiqui MS, Chetty I, et al: Analysis of the factors contributing to vertebral compression fractures after spine stereotactic radiosurgery. Int J Radiat Oncol Biol Phys 97:236-245, 2017

8. Cabanillas ME, Waguespack SG, Bronstein Y, Williams MD, 
Feng L, Hernandez M, et al: Treatment with tyrosine kinase inhibitors for patients with differentiated thyroid cancer: the M. D. Anderson experience. J Clin Endocrinol Metab 95:2588-2595, 2010

9. Chang EL, Shiu AS, Lii MF, Rhines LD, Mendel E, Mahajan A, et al: Phase I clinical evaluation of near-simultaneous computed tomographic image-guided stereotactic body radiotherapy for spinal metastases. Int J Radiat Oncol Biol Phys 59:1288-1294, 2004

10. Chang EL, Shiu AS, Mendel E, Mathews LA, Mahajan A, Allen PK, et al: Phase I/II study of stereotactic body radiotherapy for spinal metastasis and its pattern of failure. J Neurosurg Spine 7:151-160, 2007

11. Chiang A, Zeng L, Zhang L, Lochray F, Korol R, Loblaw A, et al: Pain flare is a common adverse event in steroid-naïve patients after spine stereotactic body radiation therapy: a prospective clinical trial. Int J Radiat Oncol Biol Phys 86:638-642, 2013

12. Choksi P, Papaleontiou M, Guo C, Worden F, Banerjee M, Haymart M: Skeletal complications and mortality in thyroid cancer: a population-based study. J Clin Endocrinol Metab 102:1254-1260, 2017

13. Chung C, Dawson LA, Joshua AM, Brade AM: Radiation recall dermatitis triggered by multi-targeted tyrosine kinase inhibitors: sunitinib and sorafenib. Anticancer Drugs 21:206-209, 2010

14. Cox BW, Jackson A, Hunt M, Bilsky M, Yamada Y: Esophageal toxicity from high-dose, single-fraction paraspinal stereotactic radiosurgery. Int J Radiat Oncol Biol Phys 83:e661-e667, 2012

15. Cox BW, Spratt DE, Lovelock M, Bilsky MH, Lis E, Ryu S, et al: International Spine Radiosurgery Consortium consensus guidelines for target volume definition in spinal stereotactic radiosurgery. Int J Radiat Oncol Biol Phys 83:e597e605, 2012

16. Demura S, Kawahara N, Murakami H, Abdel-Wanis ME, Kato S, Yoshioka K, et al: Total en bloc spondylectomy for spinal metastases in thyroid carcinoma. J Neurosurg Spine 14:172-176, 2011

17. Elibe E, Boyce-Fappiano D, Ryu S, Siddiqui MS, Wen N, Lee I, et al: Stereotactic radiosurgery for multiple myeloma of the spine. J Radiat Oncol 7:37-44, 2018

18. Fine JP, Gray RJ: A proportional hazards model for the subdistribution of a competing risk. J Am Stat Assoc 94:496509, 1999

19. Folkert MR, Bilsky MH, Tom AK, Oh JH, Alektiar KM, Laufer I, et al: Outcomes and toxicity for hypofractionated and single-fraction image-guided stereotactic radiosurgery for sarcomas metastasizing to the spine. Int J Radiat Oncol Biol Phys 88:1085-1091, 2014

20. Garg AK, Shiu AS, Yang J, Wang XS, Allen P, Brown BW, et al: Phase $1 / 2$ trial of single-session stereotactic body radiotherapy for previously unirradiated spinal metastases. Cancer 118:5069-5077, 2012

21. Gerszten PC, Burton SA, Ozhasoglu C, Welch WC: Radiosurgery for spinal metastases: clinical experience in 500 cases from a single institution. Spine (Phila Pa 1976) 32:193-199, 2007

22. Ghia AJ, Chang EL, Bishop AJ, Pan HY, Boehling NS, Amini B, et al: Single-fraction versus multifraction spinal stereotactic radiosurgery for spinal metastases from renal cell carcinoma: secondary analysis of Phase I/II trials. J Neurosurg Spine 24:829-836, 2016

23. Gomez DR, Blumenschein GR Jr, Lee JJ, Hernandez M, Ye $\mathrm{R}$, Camidge DR, et al: Local consolidative therapy versus maintenance therapy or observation for patients with oligometastatic non-small-cell lung cancer without progression after first-line systemic therapy: a multicentre, randomised, controlled, phase 2 study. Lancet Oncol 17:1672-1682, 2016
24. Gomez DR, Hunt MA, Jackson A, O'Meara WP, Bukanova EN, Zelefsky MJ, et al: Low rate of thoracic toxicity in palliative paraspinal single-fraction stereotactic body radiation therapy. Radiother Oncol 93:414-418, 2009

25. Ho JC, Tang C, Deegan BJ, Allen PK, Jonasch E, Amini B, et al: The use of spine stereotactic radiosurgery for oligometastatic disease. J Neurosurg Spine 25:239-247, 2016

26. Klekamp J, Samii H: Surgical results for spinal metastases. Acta Neurochir (Wien) 140:957-967, 1998

27. Kushchayeva YS, Kushchayev SV, Carroll NM, Felger EA, Links TP, Teytelboym OM, et al: Spinal metastases due to thyroid carcinoma: an analysis of 202 patients. Thyroid 24:1488-1500, 2014

28. Laufer I, Rubin DG, Lis E, Cox BW, Stubblefield MD, Yamada Y, et al: The NOMS framework: approach to the treatment of spinal metastatic tumors. Oncologist 18:744-751, 2013

29. Levine AM, Coleman C, Horasek S: Stereotactic radiosurgery for the treatment of primary sarcomas and sarcoma metastases of the spine. Neurosurgery 64 (2 Suppl):A54-A59, 2009

30. Mehta K, Kaubisch A, Tang J, Pirlamarla A, Kalnicki S: Radiation recall dermatitis in patients treated with sorafenib. Case Rep Oncol Med 2018:2171062, 2018

31. Muresan MM, Olivier P, Leclère J, Sirveaux F, Brunaud L, Klein M, et al: Bone metastases from differentiated thyroid carcinoma. Endocr Relat Cancer 15:37-49, 2008

32. Naoum GE, Morkos M, Kim B, Arafat W: Novel targeted therapies and immunotherapy for advanced thyroid cancers. Mol Cancer 17:51, 2018

33. Oh D, Park HC, Lim HY, Yoo BC: Sorafenib-triggered radiation recall dermatitis with a disseminated exanthematous reaction. Radiat Oncol J 31:171-174, 2013

34. Palma DA, Olson RA, Harrow S, Gaede S, Louie AV, Haasbeek C, et al: Stereotactic Ablative Radiation Therapy for the Comprehensive Treatment of Oligometastatic Tumors (SABR-COMET): results of a randomized trial. Int J Radiat Oncol Biol Phys 102:S3-S4, 2018

35. Pan HY, Allen PK, Wang XS, Chang EL, Rhines LD, Tatsui $\mathrm{CE}$, et al: Incidence and predictive factors of pain flare after spine stereotactic body radiation therapy: secondary analysis of phase 1/2 trials. Int J Radiat Oncol Biol Phys 90:870876,2014

36. Redmond KJ, Robertson S, Lo SS, Soltys SG, Ryu S, McNutt $\mathrm{T}$, et al: Consensus contouring guidelines for postoperative stereotactic body radiation therapy for metastatic solid tumor malignancies to the spine. Int J Radiat Oncol Biol Phys 97:64-74, 2017

37. Sahgal A, Larson DA, Chang EL: Stereotactic body radiosurgery for spinal metastases: a critical review. Int J Radiat Oncol Biol Phys 71:652-665, 2008

38. Sahgal A, Weinberg V, Ma L, Chang E, Chao S, Muacevic A, et al: Probabilities of radiation myelopathy specific to stereotactic body radiation therapy to guide safe practice. Int $\mathbf{J}$ Radiat Oncol Biol Phys 85:341-347, 2013

39. Shiu AS, Chang EL, Ye JS, Lii M, Rhines LD, Mendel E, et al: Near simultaneous computed tomography image-guided stereotactic spinal radiotherapy: an emerging paradigm for achieving true stereotaxy. Int J Radiat Oncol Biol Phys 57:605-613, 2003

40. Surveillance, Epidemiology, and End Results Program (SEER): Cancer stat facts: thyroid cancer. Bethesda, MD NCI (https://seer.cancer.gov/statfacts/html/thyro.html) [Accessed December 20, 2019]

41. Tang C, Hess K, Bishop AJ, Pan HY, Christensen EN, Yang $\mathrm{JN}$, et al: Creation of a prognostic index for spine metastasis to stratify survival in patients treated with spinal stereotactic radiosurgery: secondary analysis of mature prospective trials Int J Radiat Oncol Biol Phys 93:118-125, 2015

42. van der Linden YM, Dijkstra SPDS, Vonk EJA, Marijnen 
CAM, Leer JWH: Prediction of survival in patients with metastases in the spinal column: results based on a randomized trial of radiotherapy. Cancer 103:320-328, 2005

43. Yamada Y, Bilsky MH, Lovelock DM, Venkatraman ES, Toner S, Johnson J, et al: High-dose, single-fraction imageguided intensity-modulated radiotherapy for metastatic spinal lesions. Int J Radiat Oncol Biol Phys 71:484-490, 2008

44. Zelefsky MJ, Greco C, Motzer R, Magsanoc JM, Pei X, Lovelock M, et al: Tumor control outcomes after hypofractionated and single-dose stereotactic image-guided intensity-modulated radiotherapy for extracranial metastases from renal cell carcinoma. Int J Radiat Oncol Biol Phys 82:1744-1748, 2012

\section{Disclosures}

Dr. Rhines is a consultant for Stryker and Globus.

\section{Author Contributions}

Conception and design: Boyce-Fappiano, Pezzi, Solimman, Bernstein. Acquisition of data: Boyce-Fappiano, Pezzi, Taku, Bernstein. Analysis and interpretation of data: Boyce-Fappiano, Pezzi, Allen. Drafting the article: Boyce-Fappiano, Gjyshi, Allen. Critically revising the article: Boyce-Fappiano, Gjyshi, Pezzi, Solimman, Taku, Bernstein, Cabanillas, Amini, Tatsui, Rhines, Wang, Briere, Yeboa, Bishop, Li, Ghia. Reviewed submitted version of manuscript: all authors. Approved the final version of the manuscript on behalf of all authors: Boyce-Fappiano. Statistical analysis: Allen.

\section{Correspondence}

David Boyce-Fappiano: MD Anderson Cancer Center, Houston, TX.drboyce@mdanderson.org. 